\title{
The Effect of Berberis Vulgaris Extract on Transaminase Activities in Non- Alcoholic Fatty Liver Disease
}

\author{
Raziye Iloon Kashkooli ${ }^{1}$; Seyed Saeed Najafi ${ }^{1,}$; Farkhondeh Sharif ${ }^{1}$; Azadeh Hamedi ${ }^{2}$; \\ Mohammad Kazem Hoseini Asl ${ }^{3}$; Majid Najafi Kalyani ${ }^{4}$; Mehdi Birjandi ${ }^{5}$ \\ ${ }^{1}$ Department of Medical Surgical, School of Nursing and Midwifery, Shiraz University of Medical Sciences, Shiraz, IR Iran \\ ${ }^{2}$ Department of Pharmaceutical Biotechnology, School of Pharmacy, Shiraz University of Medical Sciences, Shiraz, IR Iran \\ ${ }^{3}$ Gastroenterohepatology Research Center, Nemazee Hospital, Shiraz University of Medical Sciences, Shiraz, IR Iran \\ 4 Department of Medical Surgical, School of Nursing, Fasa University of Medical Sciences, Fasa, IR Iran \\ 5 Department of Biostatistics, School of Public Health, Lorestan University of Medical Sciences, Khoramabad, IR Iran \\ * Corresponding Author: Seyed Saeed Najafi, Department of Medical Surgical Nursing, School of Nursing and Midwifery, Shiraz University of Medical Sciences, Shiraz, IR Iran. Tel: \\ +98-7136474254, E-mail:s_najafi44@yahoo.com
}

Received: November 1, 2014; Revised: January 1, 2015; Accepted: January 11, 2015

\begin{abstract}
Background: Non-alcoholic fatty liver disease(NAFLD) is the most prevalent liver disorder in western countries and an important cause of liver cirrhosis, as well as liver failure. Up to now, $20-40 \%$ of the individuals suffer from this disorder and its prevalence is estimated around 5-30\% in Asia. The NAFLD is one of the most prevalent causes for increases in liver enzymes and has a close relationship with obesity, dyslipidemia, hypertension, and type II diabetes. However, no definite treatment has been identified for it yet.

Objectives: The present study aimed to investigate the effect of berberis vulgaris extract in inducing changes in liver enzymes levels.

Patients and Methods: The present clinical trial was conducted on 80 patients, including 32 males (40\%) and 48 females (60\%), who were randomly assigned into two groups of case and control. All the patients had ultrasound evidence of lipid accumulation in the liver and increases in liver enzymes. The case group received two capsules $(750 \mathrm{mg})$ containing berberis vulgaris extract every day for 3 months, while the control group was treated with placebo. The weight, liver transaminases levels and lipid profiles of the two groups were assessed before, during, and after the study.

Results: In the case group, the mean serum levels of alanine transaminase (ALT) and aspartate transaminase (AST) decreased from 49 to 27.48 and 48.22 to $29.8 \mathrm{u} / \mathrm{L}$, respectively, which was statistically significant compared to the control group $(\mathrm{P}<0.001, \mathrm{P}<0.001)$. In the control group, the mean of ALT and AST decreased from 50.4 to 46.8 and 45.7 to $44.9 \mathrm{u} / \mathrm{L}$, respectively. The difference was not statistically significant. In addition, a significant decrease was observed in weight, triglycerides, and cholesterol, while no significant change was found in fasting blood sugar, high-density lipoprotein cholesterol (HDL-C), and low-density lipoprotein cholesterol (LDL).

Conclusions: Considering the significant decrease in the liver enzymes, triglycerides and cholesterol after using berberis vulgaris extract, further studies with larger sample sizes will identify the accurate dose as well as duration of consumption for this extract, to recommend in the treatment of patients with NAFLD.
\end{abstract}

Keywords:Non-Alcoholic Fatty Liver Disease; Alanine Transaminase; Aspartate Transaminase; Triglycerides; Berberis

\section{Background}

Non-alcoholic fatty liver disease (NAFLD) refers to a situation in which triglycerides are accumulated in the liver cells of individuals with no history of alcohol abuse or those who use little alcohol (1). This disease is the most prevalent liver disorder in western industrial countries, and about $20-40 \%$ of the members of these societies suffer from NAFLD, with a prevalence estimate of $5-30 \%$ in Asia $(2,3)$. The prevalence of NAFLD in the general population of Iran has been reported to of about 2.1\% (4). The NAFLD has a wide range of clinical presentations: several patients may only suffer from the accumulation of lipid in their liver tissue, while the disease may progress to non-alcoholic steatohepatitis (NASH) in several others (5, $6)$. Moreover, this disorder may lead to liver fibrosis, cirrhosis, and failure, in $20 \%$ of these patients $(5,7,8)$. Up to now, the pathogenesis of NAFLD has not been identified however. It has been shown to have a close relationship with obesity, dyslipidemia, hypertension, and type II diabetes $(2,6,8)$. Recently, this disorder has been considered as a major cause of liver cirrhosis and failure and is the most prevalent cause of increases in the values of liver function tests $(7,9,10)$.

Up to present, due to the fact that the accurate pathogenesis of NAFLD has not been identified, no medication is available for its treatment (11). Only a limited number of studies have been conducted on the issue (12). Nevertheless, decreasing the obesity and treating hyperlipidemia as well as diabetes mellitus are the measures which can be taken toward decreasing the probability of NAFLD (11). Nowadays, the use of herbal medicines has consider-

Copyright ( 2015, Kowsar Corp. This is an open-access article distributed under the terms of the Creative Commons Attribution-NonCommercial 4.0 International License (http://creativecommons.org/licenses/by-nc/4.0/) which permits copy and redistribute the material just in noncommercial usages, provided the original work is properly cited. 
ably increased in Europe and the US, leading to about 65\% use of herbal medicines in these countries (13).

Berberis vulgaris belongs to the Berberidaceae family and is one of the native plants of Iran, which is widely used in traditional medicine. Almost, 22 alkaloids have been identified in the root, leaf, and fruits of this plant (13); the most important of which is berberine, which can reduce weight, improve dyslipidemia, and increase insulin sensitivity (14). Similarly, it is expected to reduce the transaminases in NAFLD.

\section{Objectives}

The present study was conducted to investigate the effect of berberis vulgaris on NAFLD patients in Iran.

\section{Patients and Methods}

In this study, a randomized controlled trial (IRCT: 201202068505N2) design was employed. After obtaining approval of the Ethics Committee (Registration Number: Ct-91-6081) of Shiraz University of Medical Sciences, Shiraz, Iran, the present clinical trial was conducted between October 2011 and May 2012 on 99 patients (42.42\% male and $57.57 \%$ female), who had referred to the Motahari Clinic affiliated to Shiraz University of Medical Sciences, Shiraz, Iran, for treatment of their liver diseases. The patients were selected by purposive sampling, based on the inclusion criteria. The necessary criteria for the diagnosing NASH included having ultrasound evidence of fatty liver (grade II) and increased liver enzymes (one to three times more than the normal level). On the other hand, the exclusion criteria of the study regarded the patients suffering from liver diseases resulting from causes other than NAFLD, such as hepatitis B or C, autoimmune hepatitis and drug abuse, type I diabetes, type II diabetes with 1 year duration using glucose-lowering drugs, pregnancy, breast feeding, alcohol consumption, use of medications known to affect liver tests during the previous 2 months, and having the history of psychotic diseases or severe depression.

The study subjects were randomly assigned to the case and control groups. Simple randomization was used in this study. For the randomization, we numbered the groups (case 1, control 2) then the sequence of groups was drawn up by coin tossing. The case group received $750 \mathrm{mg}$ aqueous extract of berberis vulgaris for 3 months, while the control group received placebo. Both groups received their medications in the form of capsules (with identical appearance).

After berberis vulgaris was purchased, it was confirmed by a botanist and cleaned. Then, it was extracted by a specialist in the Medicinal Plants Laboratory of Shiraz School of Pharmacy, Shiraz, Iran, then concentrated in a rotary evaporator, and dried using the freeze dryer. In addition, microbial control experiments were performed in order to ensure that pathogens, such as Salmonella, Escherichia coli, Staphylococcus, and Bacillus cereus, did not exist in the berberis vulgaris extract. The two groups' weight, total cholesterol, triglyceride, high-density lipoprotein cholesterol (HDL-C), low-density lipoprotein cholesterol (LDL-C), and fasting blood glucose (FBG) were measured before and 90 days after the intervention. Besides, the alanine transaminase (ALT) and aspartate transaminase (AST) enzymes' levels were measured before and 45 and 90 days after the intervention. It should be noted that these experiments were carried out using Biosystem kits (Biosystem S.A., Barcelona, Spain) and through the spectrophotometry method.

Both groups received two capsules every day, one before breakfast and one before dinner, and the probable complications were followed up through telephone contacts. During the first week, four cases of mild disorders were reported in the case group, three of which were diarrhea and the other one was mild constipation.

Of the total 99 patients, 19 were excluded from the study due to lack of cooperation and completion of treatment period, and finally, 40 patients were enrolled into each study group for analysis.

The collected data were analyzed in the SPSS statistical software (v. 16) (SPSS Inc., Chicago, ILL, USA) using independent sample t-test before the intervention and repeated measurement test after the intervention.

\section{Results}

A number of 19 patients were excluded from the study resulting in a final number of 40 subjects enrolled in each group. In the case group, 19 patients (47.5\%) were male, while 21 (52.5\%) were female. On the other hand, the control group included 13 males (33\%) and 27 females (67\%). The mean age of the patients in the case and control groups was 43.65 and 42.97 years, respectively. The mean weights of the case and control subjects were 80.24 and $83.62 \mathrm{~kg}$, respectively.

According to the results, the case group's mean weight decreased from $80.24 \mathrm{~kg}$ at the beginning of the study to $78.71 \mathrm{~kg}$ at the end, which was statistically significant compared to the control group $(\mathrm{P}<0.001)$. The case group's mean serum level of ALT was 49 and $27.48 \mathrm{u} / \mathrm{L}$ before and after the intervention, respectively $(\mathrm{P}<0.001)$, while it was measured as 50.4 and $46.8 \mathrm{u} / \mathrm{L}$, respectively, in the control group $(\mathrm{P}>0.05)$. Also, the mean AST level of the case group was 48.22 and $29.8 \mathrm{u} / \mathrm{L}$ before and after the intervention, respectively $(\mathrm{P}<0.001)$, while it was measured as 45.7 and $44.9 \mathrm{u} / \mathrm{L}$, respectively, in the control group $(\mathrm{P}>$ 0.05). The mean FBG in the case group was 87.95 and 85.70 $\mathrm{mg} / \mathrm{dL}$ before and after the intervention, respectively ( $\mathrm{P}$ $>0.05$ ), while it was 91.60 and $93.62 \mathrm{mg} / \mathrm{dL}$, respectively in the control group $(\mathrm{P}>0.05)$. Moreover, the mean level of triglycerides in the case group was 219.22 and 167.20 $\mathrm{mg} / \mathrm{dl}$ before and after the intervention, respectively $(\mathrm{P}<$ 0.001 ), while it was measured to be 214.7 and $201.47 \mathrm{mg} /$ $\mathrm{dL}$, respectively, in the control group $(\mathrm{P}>0.05)$. In addition, the mean serum level of total cholesterol in the case group was 211.40 and $186.05 \mathrm{mg} / \mathrm{dL}$ before and after the in- 
Iloon Kashkooli R et al.

tervention, respectively (<0.001), while it was 225.38 and $\quad 220.80 \mathrm{mg} / \mathrm{dL}$, respectively, in the control group $(\mathrm{P}>0.05)$.

Table 1. Demographic Characteristics of the Two Study Groups

\begin{tabular}{|c|c|c|c|c|c|}
\hline Group & No. & Age, y & Female, No. (\%) & Male, No. (\%) & Weight, kg \\
\hline Case & 40 & 43.65 & $21(52.5)$ & $19(47.5)$ & 80.24 \\
\hline Control & 40 & 42.97 & $27(67)$ & $13(33)$ & 83.62 \\
\hline
\end{tabular}

Table 2. Changes in Each Variable From the Beginning to the end of the Study ${ }^{a}$

\begin{tabular}{|c|c|c|c|c|c|c|c|c|}
\hline \multirow[t]{3}{*}{ Variable } & \multicolumn{3}{|c|}{ P Value } & \multicolumn{3}{|c|}{ Berberis Vulgaris $(n=40)$} & \multicolumn{2}{|c|}{ Placebo $(n=40)$} \\
\hline & \multirow{2}{*}{$\begin{array}{c}\text { Before } \\
\text { Treatment }\end{array}$} & \multirow{2}{*}{$\begin{array}{c}\text { Forty-fifth } \\
\text { day }\end{array}$} & \multirow{2}{*}{$\begin{array}{c}\text { After } \\
\text { Treatment }\end{array}$} & \multirow{2}{*}{$\begin{array}{c}\text { Before } \\
\text { Treatment }\end{array}$} & \multirow{2}{*}{$\begin{array}{c}\text { Forty-fifth } \\
\text { day }\end{array}$} & \multirow{2}{*}{$\begin{array}{c}\text { After } \\
\text { Treatment }\end{array}$} & \multicolumn{2}{|c|}{ Berberis Vulgaris vs. Placebo } \\
\hline & & & & & & & Baseline & After Treatment \\
\hline Weight, kg & $83.62 \pm 9.33$ & $83.52 \pm 9.10$ & $83.53 \pm 9.31$ & $80.24 \pm 11.68$ & $79.13 \pm 11.48$ & $78.71 \pm 11.31$ & 0.1 & $\mathrm{P}<0.001$ \\
\hline ALT, $\mathbf{U} / \mathbf{l}$ & $50.40 \pm 9.38$ & $49.90 \pm 12.17$ & $46.80 \pm 9.87$ & $49.0 \pm 11.44$ & $36.42 \pm 12.10$ & $29.08 \pm 12.99$ & 0.5 & $\mathrm{P}<0.001$ \\
\hline AST, U/l & $45.70 \pm 8.19$ & $46.32 \pm 10.08$ & $44.98 \pm 9.69$ & $48.22 \pm 9.82$ & $37.02 \pm 12.18$ & $2748 \pm 12.50$ & 0.2 & $\mathrm{P}<0.001$ \\
\hline FBG, mg/dL & $91.60 \pm 16.24$ & $93.45 \pm 13.39$ & $93.62 \pm 16.20$ & $87.95 \pm 13.65$ & $86.47 \pm 14.5$ & $85.70 \pm 15.28$ & 0.2 & $P=0.18$ \\
\hline TG, mg/dL & $214.7 \pm 55.29$ & & $201.47 \pm 60.60$ & $219.22 \pm 72.14$ & & $167.20 \pm 69.32$ & 0.7 & $\mathrm{P}<0.001$ \\
\hline CHOL, mg/dL & $225.38 \pm 43.17$ & & $220.80 \pm 39.49$ & $211.40 \pm 30.93$ & & $186.05 \pm 36.51$ & 0.1 & $\mathrm{P}<0.001$ \\
\hline LDL, mg/dL & $139.86 \pm 34.14$ & & $134.33 \pm 30.69$ & $130.68 \pm 27.79$ & & $116.13 \pm 32.47$ & 0.1 & $P=0.054$ \\
\hline HDL, mg/dL & $41.05 \pm 8.66$ & & $41.22 \pm 8.34$ & $36.87 \pm 7.43$ & & $37.0 \pm 7.17$ & 0.1 & $P=0.96$ \\
\hline
\end{tabular}

Furthermore, the mean serum level of LDL was 130.68 and $116.13 \mathrm{mg} / \mathrm{dL}$ in the case group $(\mathrm{P}>0.05)$ and 139.86 and $134.33 \mathrm{mg} / \mathrm{dL}$ in the control group $(\mathrm{P}>0.05)$, before and after the intervention, respectively. Finally, the case group's mean HDL serum level was 37.0 and $36.87 \mathrm{mg} / \mathrm{dL}$ before and after the intervention, respectively $(\mathrm{P}>0.05)$, while it counted 41.05 and $41.22 \mathrm{mg} / \mathrm{dL}$, respectively in the control group $(\mathrm{P}>0.05)$. As shown, no significant difference was found between the two groups regarding the study variables before the intervention.

\section{Discussion}

The decreases in liver transaminases (ALT and AST), cholesterol, triglyceride, and weight in the case group showed the effectiveness of berberis vulgaris. In fact, the antioxidants, as well as anti-inflammatory effects of the phenolic compounds present in berberis vulgaris demonstrate its hepatoprotective role (15-19). Shulman states that the decrease in liver triglycerides leads to the progression of insulin sensitivity and protection against type II diabetes (14). A large number of studies have also shown that NAFLD can predict type II diabetes, as well as metabolic syndrome, and therefore, treating this disorder can be an effective way of preventing type II diabetes (14).

The theory of insulin resistance, which is considered as the main mechanism in liver steatosis states that insulin resistance leads to lipid accumulation in hepatocytes through two mechanisms:

1 - Increase in lipolysis, which results in an increase in free fatty acids;
2 - Hyperinsulinemia, which increases beta oxidation in mitochondria through increasing the reabsorption of fatty acids by the hepatocytes and, consequently, leads to lipid accumulation in the hepatocytes $(20,21)$.

In general, NAFLD has a close relationship with metabolic syndrome, diabetes, hypertension, and dyslipidemia. Therefore, all the medications used for treating the metabolic disorders can improve liver disorders and it seems that insulin sensitizing agents are efficient. However, this method might not be appropriate for non-diabetic or thin patients (22).

Motalleb believes that alkaloid protoberin, which is one of the major components of berberis, has attracted much attention in the recent years and is one of the best reactive oxygen species (23).

Wei et al. investigated the effect of berberine on type II diabetes accompanied by fatty liver. That study was conducted on 30 diabetic patients who were also suffering from fatty liver. The study subjects received $500 \mathrm{mg}$ berberine pills three times a week, for 8 weeks, and the results revealed that the ALT, AST, glycated hemoglobin (HbA1C), FBG, body-mass index (BMI), LDL, triglycerides, total cholesterol, and gamma glutamyl transferase (GGT) markers had significantly decreased in comparison to the levels before the treatment (24).

In the in vitro study of Yang et al. treatment by berberine hydrochloride reduced triglycerides, LDL-C, liver transaminases and improved liver steatosis in the case group (25). In the same line, Zhang et al. revealed that berberine considerably helped to improve dyslipidemia, as well as diabetes, and significantly corrected lipid and diabetes parameters. In comparison to the placebo group, ALT, 
AST, and GGT significantly decreased in the berberine group. Also, ALT, AST, and GGT had decreased from $30 \pm 21$ to $22 \pm 14 \mathrm{IU} / \mathrm{L}(\mathrm{P}<0.001), 26 \pm 12$ to $22 \pm 7 \mathrm{IU} / \mathrm{L}(\mathrm{P}=0.006)$ and $34 \pm 20$ to $30 \pm 24 \mathrm{IU} / \mathrm{L}(\mathrm{P}=0.53)$, respectively $(26)$.

In another study, Taheri et al. investigated the effect of hydroalcoholic extract of berberis on liver enzymes activity in mice. The results showed that the hydroalcoholic extract of berberis had significantly decreased the serum ALT level, while no significant decrease was observed regarding AST (27).

Furthermore, Murugesh et al. studied the antioxidant and hepatoprotective role of berberis. In that animal study, hepatotoxicity was created in one group of mice by administration of paracetamol, and one week after starting the administration of methanolic berberis extract, the increased levels of enzymes had dropped significantly. Besides, the serum levels of AST and ALT reached the normal level, which was interpreted as hepatocyte cytoplasmic membrane repair (15). These findings are consistent with those of the present study

Motalleb et al. also came to the conclusion that berberis vulgaris extract reduced the activity of liver enzymes, while at the same time preventing the expression of alpha-fetoprotein in liver cancer (28).

Moreover, Eidi et al. investigated the hepatoprotective effect of berberis extract on the toxicity resulting from carbon tetrachloride in mice. After intraperitoneal use of three different doses of berberis for 28 days, the rate of aminotransferases had significantly decreased almost down to the normal level (29).

Ebrahimi et al. conducted a study on 57 patients with hyperlipidemia in Iran. After 8 weeks of intervention with berberis vulgaris processed in vinegar, no significant changes were observed in BMI, total cholesterol concentration and triglycerides. However, a significant decrease was found in HDL-C and LDL-C concentrations, and also in the total cholesterol to HDL-C ratio (30). Similarly, in the study by Farhadi et al. which employed 200 mg capsules of aqeous extract of berberis three times a day for 2 weeks, significantly decreased blood cholesterol and triglycerides? of 5.13\% and $17.2 \%$, respectively (31).

Another study was conducted by Yin et al. on the effectiveness and safety of berberine in the treatment of the patients with type II diabetes in China in 2008. The results revealed no significant changes regarding HDL-C and LDL-C in the berberine group during the 1st and 13th weeks. Nevertheless, a significant decrease was found in HbA1c, as well as FBG levels (32).

The findings of the present study are in agreement with those of the previous investigation. However, despite the fact that most of the study patients were nondiabetic, no significant decrease was observed in FBG. Nonetheless, it should be noted that the diabetic patients with more than 1 year duration of the disease, or who were using antidiabetic medication, were excluded from the current study. Therefore, the changes in FBG in this study cannot be generalized, and this may be considered as one of the limitations of the present research. Finally, using aminotransferase level in the follow up of NAFLD represented the other limitation of the study, as histologic findings are presently the gold standard method.

The study findings revealed the effectiveness of berberis vulgaris extract in reducing liver transaminases (ALT and AST), cholesterol, triglyceride, LDL-C, and weight. In addition, these factors have a close relationship with NAFLD. Therefore, due to its low cost and low incidence and severity of complications, berberis extract can be used as a supplementary medication in treating NAFLD.

\section{Acknowledgements}

The present article was extracted from Mrs. Iloon Kashkooli's M.Sc. thesis (No. 6088-90). The authors would like to thank the Research Vice-Chancellor of Shiraz University of Medical Sciences, Shiraz, Iran, for financially supporting the research. They are also grateful for the management of graduate school and college of nursing and midwifery for their assistance in conducting the study.

\section{Funding/Support}

This study was financially supported by the Research Vice-Chancellor of Shiraz University of Medical Sciences, Shiraz, IR Iran.

\section{References}

1. Harte AL, da Silva NF, Creely SJ, McGee KC, Billyard T, YoussefElabd EM, et al. Elevated endotoxin levels in non-alcoholic fatty liver disease. J Inflamm (Lond). 2010;7:15.

2. Light N. Epidemiology, clinical features, and diagnosis of nonalcoholic steatohepatitis. 2011;2(19):17-22.

3. Khoshbaten M, Aliasgarzadeh A, Masnadi K, Tarzamani MK, Farhang S, Babaei $\mathrm{H}$, et al. N-acetylcysteine improves liver function in patients with non-alcoholic Fatty liver disease. Hepat Mon. 2010;10(1):12-6.

4. Jamali R, Khonsari M, Merat S, Khoshnia M, Jafari E, Bahram Kalhori A, et al. Persistent alanine aminotransferase elevation among the general Iranian population: prevalence and causes. World $J$ Gastroenterol. 2008;14(18):2867-71.

5. Hajiaghamohammadi AA, Ziaee A, Samimi R. The efficacy of licorice root extract in decreasing transaminase activities in non-alcoholic fatty liver disease: a randomized controlled clinical trial. Phytother Res. 2012;26(9):1381-4.

6. Jamali R. Non-alcoholic fatty liver disease: Diagnosis and evaluation of disease severity. 2013;2(4):43-51.

7. Razavizade M, Jamali R, Arj A, Matini SM, Moraveji A, Taherkhani E. The effect of pioglitazone and metformin on liver function tests, insulin resistance, and liver fat content in nonalcoholic Fatty liver disease: a randomized double blinded clinical trial. Hepat Mon. 2013;13(5).

8. Kirovski G, Schacherer D, Wobser H, Huber H, Niessen C, Beer C, et al. Prevalence of ultrasound-diagnosed non-alcoholic fatty liver disease in a hospital cohort and its association with anthropometric, biochemical and sonographic characteristics. Int J Clin Exp Med. 2010;3(3):202-10.

9. Kotronen A, Yki-Jarvinen H, Mannisto S, Saarikoski L, KorpiHyovalti E, Oksa H, et al. Non-alcoholic and alcoholic fatty liver disease - two diseases of affluence associated with the metabolic syndrome and type 2 diabetes: the FIN-D2D survey. BMC Public Health. 2010;10:237.

10. Savadkoohi F, Hosseini-Tabatabaei MT, Shahabi Nezhad S. The frequency of fatty liver in sonography of patients withou liver 
diseases background and its correlation with blood cholesterol and triglycerid. Iranian J Tabibe Shargh. 2003;5(3):177-83.

11. Eslami L, Merat S, Nasseri-Moghaddam S. Treatment of nonalcoholic fatty liver disease (nafld): A systematic review. MEJDD. 2009;1(2):89-99.

12. Jamali R. Non-alcoholic fatty liver disease: Diagnosis and evaluation of disease severity. Thrita J Med Sci. 2013;2(2):43-51.

13. Stickel F, Schuppan D. Herbal medicine in the treatment of liver diseases. Dig Liver Dis. 2007;39(4):293-304.

14. Chang X, Yan H, Fei J, Jiang M, Zhu H, Lu D, et al. Berberine reduces methylation of the MTTP promoter and alleviates fatty liver induced by a high-fat diet in rats. J Lipid Res. 2010;51(9):2504-15.

15. Murugesh K, Yeligar VC, Maiti CB, Maity TK. Hepato protective and antioxidant role of Berberis tinctoria Lesch leaves on paracetamol induced hepatic damage in rats. 2005;4(1):64-9.

16. Das S, Das MK, Mazumder PM, Das S, Basu SP. Cytotoxic activity of methanolic extract of Berberis aristata DC on colon cancer. Global J Pharmacol. 2009;3(3):137-40.

17. Murugesh KS, Yeligar VC, Maiti CB, Maity TK. Hepato protective and antioxidant role of Berberis tinctoria Lesch leaves on paracetamol induced hepatic damage in rats. 2005(4):64-9.

18. Hanachi P, Golkho SH. Using HPLC to determination the composition and antioxidant activity of Berberis vulgaris. Europ J Sci Res. 2009;29(1):47-54.

19. Hanachi P, Kua SH, Asmah R, Motalleb G, Fauziah O. Cytotoxic Effect of Berberis vulgaris Fruit Extract on the Proliferation of Human Liver Cancer Cell Line (HepG2) and its Antioxidant Properties. Int J Canc Res. 2006;2(1):1-9.

20. Lewis JR, Mohanty SR. Nonalcoholic fatty liver disease: a review and update. Dig Dis Sci. 2010;55(3):560-78.

21. Tavangar SM, Khadem Sameni F, Derakhshan MH, Merat SH, Mehrnami A, Malekzadeh R. Correlation Of The Serum Levels Of The Alt And Ast With The Degree Of Inflammation And Fibrosis In The Liver Of Patients With Non-Alcoholic Steatohepatitis: Validation Of The Revisions Applied On The Brunt Scoring System. HAKIM. 2006;8(4):1.
22. Federico A, Trappoliere M, Loguercio C. Treatment of patients with non-alcoholic fatty liver disease: current views and perspectives. Dig Liver Dis. 2006;38(11):789-801.

23. Motalleb G, Hanachi P, Kua SH, Fauziah O, Asmah R. Evaluation of Phenolic Content and Total Antioxidant Activity in Berberis vulgaris Fruit Extract. J Biol Sci. 2005;5(5):648-53.

24. Wei J, Wu J, Jiag J.Clinical study on improvement of type diabetes mellitus complicated with fatty liver treated by berberine. Chinese J Integ Tradition West Med Liver Dis. 2004;6:334-6.

25. Yang QH, Hu SP, Zhang YP, Xie WN, Li N, Ji GY, et al. Effect of berberine on expressions of uncoupling protein-2 mRNA and protein in hepatic tissue of non-alcoholic fatty liver disease in rats. Chin J Integr Med. 2011;17(3):205-11.

26. Zhang Y, Li X, Zou D, Liu W, Yang J, Zhu N, et al. Treatment of type 2 diabetes and dyslipidemia with the natural plant alkaloid berberine. J Clin Endocrinol Metab. 2008;93(7):2559-65.

27. Taheri S, Zarei A, Changizi Ashtiyani S, Rezaei A, Zaheiri S. Evaluation of the effects of hydroalcoholic extract of Berberis vulgaris root on the activity of liver enzymes in male hypercholesterolemic rats. Avicenna J Phytomed. 2012;2(3):153-61.

28. Motalleb G, Hanachi P, Fauziah O, Asmah R. Effect of Berberis vulgaris fruit extract on alpha-fetoprotein gene expression and chemical carcinogen metabolizing enzymes activities in hepatocarcinogenesis rats. Iran J Cancer Prev. 2012;1(1):33-42.

29. Eidi A, Zarin-Ghalam J. Hepatoprotective effect of Berberis vulgaris L. extract on CCl4-induced toxicity in rats. 2011;16(3):169-73.

30. Ebrahimi-Mamaghani M, Arefhosseini SR, Golzarand M, Aliasgarzadeh A, Vahed-Jabbary M. Long-term effects of processed Berberis vulgaris on some metabolic syndrome components. Iran J Endocrinol Metabol. 2009;11(1):41-7.

31. Farhadi A, Gavadifar K. Effects of berberise vulgaris fruit extract on blood cholesterol and triglyceride in hyperlipidemic patients .J Semnan Univ Med Sci. 2008;9(3):211-6.

32. Yin J, Xing H, Ye J. Efficacy of berberine in patients with type 2 diabetes mellitus. Metabolism. 2008;57(5):712-7. 